\title{
A case of hyperosmolar hyperglycaemic state with involuntary movements - diagnostic dilemma and clinical considerations
}

\author{
Hanisah Abd Hamid', Nor-Aini Umar', Hanita Othman², Srijit Das²
}

\author{
${ }^{1}$ Department of Pathology, Universiti Kebangsaan Malaysia Medical Centre, \\ Kuala Lumpur, Malaysia \\ 2Department of Anatomy, Universiti Kebangsaan Malaysia Medical Centre, \\ Kuala Lumpur, Malaysia
}

Submitted: 17 August 2009

Accepted: 14 September 2009

Arch Med Sci 2010; 6, 6: 987-990

DOI: 10.5114/aoms.2010.19315

Copyright $\odot 2010$ Termedia \& Banach

\section{Abstract}

Hyperosmolar hyperglycaemic state (HHS) is a medical emergency which needs immediate medical intervention. A 37-year-old Chinese woman with a history of hypertension attended the Emergency Department. She had a two-day history of involuntary movement, i.e. chorea of the upper limbs, preceded by a oneweek history of upper respiratory tract infection. She also had polyuria and polydipsia, although she was never diagnosed as diabetic. The main aim of reporting the present case was to highlight the importance of biochemical investigations involved in the diagnosis of involuntary movements.

Key words: hyperglycaemic hyperosmolar state, involuntary movement, treatment

\section{Introduction}

Seizures are common presenting manifestations in patients with nonketotic hyperglycaemic (NKH) hyperosmolar state [1]. Previous research reports have labelled diabetic ketoacidosis (DKA) and the hyperosmolar hyperglycaemic state (HHS) as important life-threatening emergencies with a mortality rate of HHS reaching up to $9.2 \%$ [2].

A 37-year-old Chinese woman attended the emergency department of Universiti Kebangsaan Malaysia Medical Centre (UKMMC) with complaints of involuntary movement, i.e. chorea of the upper limbs. The preliminary investigations showed hyperosmolarity and hyperglycaemic state that led to an early diagnosis of acute on chronic renal failure. Interestingly, the involuntary movements disappeared with adequate treatment of the metabolic state. The importance of an early diagnosis of HHS with all possible biochemical investigations is discussed in the present paper. We also stress the fact that by focusing on the clinical presentation alone, one may delay arrival at a proper diagnosis of HHS. An early biochemical investigation regarding estimation of glucose may be necessary.

\section{Case report}

Prior ethical consent was obtained to report this case report. A 37-yearold Chinese, unmarried woman with a history of hypertension was brought in to the Emergency Department of UKMMC with a two-day history of involuntary movements of the upper limbs, i.e. chorea, preceded by a oneweek history of upper respiratory tract infection. She also complained of

\author{
Correspondence author: \\ Assoc. Prof. Dr. \\ Nor-Aini Umar, MD, DCP \\ Department of Pathology \\ Universiti Kebangsaan \\ Malaysia Medical Centre \\ Jalan Yaacob Latiff, Bandar \\ Tun Razak \\ 56000 Cheras, Kuala Lumpur \\ Malaysia \\ Phone: +6 0391455376 \\ Fax: +6 0391738255 \\ E-mail: nau@ppukm.ukm.my
}


Table I. Biochemical investigations performed on admission

\begin{tabular}{|c|c|}
\hline Parameter & Result \\
\hline Creatinine $(62-106 \mu \mathrm{mol} / \mathrm{l})$ & 229 \\
\hline Sodium (135-150 mmol/l) & 127 \\
\hline Potassium (3.5-5.0 mmol/l) & 4.0 \\
\hline Urea $(2.5-6.4 \mathrm{mmol} / \mathrm{l})$ & 21.8 \\
\hline Magnesium (0.60-1.10 mmol/l) & 1.43 \\
\hline Phosphate $(0.71-1.36 \mathrm{mmol} / \mathrm{l})$ & 1.91 \\
\hline Total protein $(67-88 \mathrm{~g} / \mathrm{l})$ & 81 \\
\hline Albumin $(35-50 \mathrm{~g} / \mathrm{l})$ & 35 \\
\hline ALP (32-104 U/l) & 192 \\
\hline $\operatorname{ALT}(<44 \mathrm{U} / \mathrm{l})$ & 47 \\
\hline Cr. Ca 2 (2.14-2.58 mmol/l) & 2.60 \\
\hline Cholesterol (<5.7 mmol/l) & 11.94 \\
\hline $\mathrm{HDL}(>1.20 \mathrm{mmol} / \mathrm{l})$ & 1.42 \\
\hline $\mathrm{LDL}(<3.80 \mathrm{mmol} / \mathrm{l})$ & 1.83 \\
\hline $\mathrm{TG}(<1.40 \mathrm{mmol} / \mathrm{l})$ & 19.12 \\
\hline $\mathrm{HBA}_{1 \mathrm{c}}(4.4-6.4 \%)$ & 15.9 \\
\hline FBS (3.0-6.7 mmol/l) & 35.9 \\
\hline CRP $(0-0.5 \mathrm{mg} / \mathrm{dl})$ & 7.08 \\
\hline ESR $(1-20 \mathrm{~mm} / \mathrm{hr})$ & 96 \\
\hline \multicolumn{2}{|l|}{ ABG } \\
\hline $\mathrm{BE}(-3-+3)$ & -3.5 \\
\hline $\mathrm{PCO}_{2}(35-45)$ & 93.1 \\
\hline PH (7.35-7.45) & 7.39 \\
\hline $\mathrm{PO}_{2}(65-100)$ & 66.9 \\
\hline SBC (22-26) & 21.5 \\
\hline Urine dipstick & $\begin{array}{l}\text { Glu3+ } \\
\text { Blood 1+ } \\
\text { PH } 6.5 \\
\text { Leu 2+ }\end{array}$ \\
\hline Urine ketone & + \\
\hline Protein creat. index $(<0.02 \mathrm{~g} / \mathrm{mmol})$ & 0.05 \\
\hline Urine sodium (mmol/l) & 24 \\
\hline Urine osmolality (50-1200 mOsm/kg) & 550 \\
\hline Serum osmolality (275-295 mOsm/kg) & 358 \\
\hline ACTH random $(0-46 \mathrm{pg} / \mathrm{ml})$ & 19.60 \\
\hline Cortisol random(am) (68-469 nmol/l) & 639 \\
\hline PTH (1.3-7.6 pmol/l) & 12.7 \\
\hline
\end{tabular}

polyuria and polydipsia. There was a history of loss of appetite and weight.

Examination revealed a mildly dehydrated patient, who was otherwise alert and oriented. She was afebrile $\left(37.5^{\circ} \mathrm{C}\right)$ with blood pressure recording of 130/90 mm Hg; heart rate of 70 beats/min and oxygen saturation $\left(\mathrm{SaO}_{2}\right)$ of $93 \%$ under 3 litres via nasal prongs. Her weight and height were $71 \mathrm{~kg}$ and $156 \mathrm{~cm}$, respectively. The waist circumference was $108 \mathrm{~cm}$ with the body mass index (BMI) being 29 . She had truncal obesity, buffalo hump and cushingoid facies (moon face with acne).

Her respiratory examination showed bilateral lung crepitations with inspiratory rhonchi and a prolonged expiratory phase. Involuntary movements of both upper limbs were diagnosed as chorea. On examining the central nervous system, including the visual field, reflexes were found to be unremarkable. There were generalized multiple white patches on both upper and lower limbs.

As displayed in Table I, the baseline biochemical investigations showed severe hyperglycaemia (35.9 mmol/l), high serum osmolality (358 mOsm/kg), elevated urea: creatinine ratio (> $30: 1)$, trace ketonuria with normal arterial blood gases $(\mathrm{pH} 7.39$, bicarbonate 21.5).

On admission, all the laboratory investigational values were consistent with HHS. Her fasting blood sugar showed severe hyperglycaemia $(35.9 \mathrm{mmol} / \mathrm{l})$ that suggested undiagnosed diabetes melitus (DM). This was further supported by her initial glycated haemoglobin, which showed severe chronic hyperglycaemia (15.9\%). Fasting lipid profile revealed severe hypertriglyceridaemia $(19.12 \mathrm{mmol} / \mathrm{l})$.

A diagnosis of acute on chronic kidney failure due to severe dehydration secondary to HHS was made and the patient was transferred to the medical ward. She was aggressively rehydrated with intravenous fluid. Insulin infusion was instituted with strict monitoring of glucose and input output chart. A central venous pressure line was inserted to monitor the intravascular volume. Intravenous Augmentin and azithromycin treatment with 8 hourly Ventolin nebuliser for pneumonia was carried out. Interestingly, the chorea resolved completely with appropriate treatment.

\section{Discussion}

This case in the young patient was unique as the involuntary movement, i.e. chorea, was the main presenting symptom of the HHS with previously undiagnosed type $2 \mathrm{DM}$. We arrived at the diagnosis of type 2 DM. Other differential diagnosis could include type 1 DM, diabetes insipidus and diabetic ketoacidosis.

The high osmolarity contributed to the neurological symptoms observed in HHS. These focal neurological symptoms can include myoclonic jerks, chorea, nystagmus, and Babinski's signs, seizures and stroke [3]. Interestingly, the focal neurological deficit reversed completely with adequate treatment and correction of the metabolic abnormalities. Delayed treatment could result in mental obtundation with less than $20 \%$ of patients 
presenting with coma [3]. However, there are many disorders that could also present with similar neurological changes apart from HHS. Thus, by focusing solely on the clinical presentation one may delay the diagnosis of HHS unless the glucose level is obtained early in the presentation.

$\mathrm{HHS}$ is a serious acute metabolic complication of diabetes mellitus. Higher HHS mortality rates compared to DKA (i.e. between 10\% and 50\%) are reported to respond to appropriate treatment [4]. $\mathrm{HHS}$ can also be the initial presentation of diabetes in $30 \%$ to $40 \%$ of patients, especially in the elderly, obese and those with decreased renal function [4, 5]. HHS is more common in type $2 \mathrm{DM}$ as compared to type $1 \mathrm{DM}[3,4]$. As per earlier reports, successful treatment of DKA and HHS needs immediate correction of dehydration, hyperglycaemia, and electrolyte imbalances; proper identification of comorbid precipitating events; and also frequent patient monitoring [6]. An earlier protocol stated that the initial laboratory investigation in patients with suspected DKA or HHS should focus mainly on the plasma glucose, blood urea nitrogen/creatinine, serum ketones, electrolytes, osmolality, urinalysis, urine ketones, initial arterial blood gases, complete blood count with differential, and electrocardiogram [7]. Interestingly, in the present case, the patient had all possible risks of developing HHS.

HHS classically presents with an insidious onset of osmotic symptoms, i.e. polyuria and polydipsia, that occur for several weeks, followed by signs and symptoms of profound dehydration. In the present case, the patient was not known to be diabetic. Thus, there was under-recognition of signs and symptoms of uncontrolled diabetes, thereby leading to the development of HHS.

Initial physical examination revealed that the patient was afebrile despite her underlying pneumonia and urinary tract infection. HHS might have caused peripheral vasodilatation, thereby explaining the afebrile condition of the patient. In addition, obesity and diabetic dermatopathy indicated insulin resistance in this patient. However, all these clinical presentations of HHS might be similar to DKA, and a definite diagnosis must be confirmed through laboratory investigation. We advocate that the precipitating causes and other co-morbidities associated with HHS should also be included as part of the initial laboratory evaluation.

The classical picture of HHS in this patient included insidious onset of osmotic symptoms, i.e. polyuria and polydipsia, followed by signs and symptoms of profound dehydration. The underrecognition of the signs and symptoms of uncontrolled diabetes contributed to the development of HHS.

On the day of admission, measured serum osmolality (358 mOsm/kg) was high, corresponding to urine osmolality $(550 \mathrm{mOsm} / \mathrm{kg}$ ). Presence of high urinary sodium with severe hyperglycaemia indicated osmotic diuresis, which was consistent with the symptoms (i.e. polyuria and polydipsia). There was an osmolar gap as there was a discrepancy between the measured (358 $\mathrm{mmol} / \mathrm{l})$ and calculated serum osmolality (316 mmol/l) as a consequence of severe dehydration and hyperlipidaemia.

The renal function test revealed acute on chronic kidney failure as her previous creatinine level was $136 \mu \mathrm{mol} / \mathrm{l}$ at the time when the diagnosis of hypertension was made. During the current admission, her renal profile values were:- sodium $127 \mathrm{mmol} / \mathrm{l}$; potassium $4.0 \mathrm{mmol} / \mathrm{l}$; serum urea and creatinine of 21.8 and $229 \mu \mathrm{mol} / \mathrm{l}$, respectively giving a urea : creatinine ratio more than $30: 1$. This indicated pre-renal azotaemia as a consequence of severe dehydration. This was further supported by her urine : serum osmolarity ratio of more than 1.5 : 1 . Furthermore, the magnesium $(1.43 \mathrm{mmol} / \mathrm{l})$, phosphate $(1.91 \mathrm{mmol} / \mathrm{l})$, and calcium $(2.60 \mathrm{mmol} / \mathrm{l})$ were also raised. Her corrected sodium (Table I) was normal (136 mmol/l) even though the measured sodium was low (127 mmol/l), which indicated pseudohyponatraemia due to the presence of severe hyperglycaemia and hypertriglyceridaemia.

The liver function test showed mild hypoalbuminaemia (35 g/l) that was most likely due to underlying chronic illness or diabetic nephropathy with evidence of significantly increased protein creatinine index. Her total protein and transaminase enzyme, ALP and ALT ( $81 \mathrm{~g} / \mathrm{l}, 192 \mathrm{U} / \mathrm{l}$, $47 \mathrm{U} / \mathrm{l})$ were raised on initial presentation due to dehydration. Mildly elevated alkaline phosphatase was attributed to the dehydration or secondary to renal osteodystrophy. This was further confirmed by her serum calcium, which markedly decreased $(1.87 \mathrm{mmol} / \mathrm{l})$ after the aggressive treatment, which revealed the true hypocalcaemia as a complication of chronic kidney disease and increase of parathyroid hormone level (12.7 pmol/l).

Arterial blood gas was normal ( $\mathrm{pH} 7.39$, bicarbonate 21.5) and it ruled out DKA. Inflammatory markers such as C-reactive protein (CRP) and erythrocyte sedimentation rate (ESR) were markedly elevated because of ongoing infection or inflammation. Urinalysis showed marked glycosuria (3+), leukocytosis (2+) with trace ketonuria. Full blood count showed relative polycythaemia ( $\mathrm{Hb}$ 17.1) with haematocrit (48.5\%) as a consequence of severe dehydration. White cell count $\left(\right.$ WBC) was high $\left(18.8 \times 10^{9} \mathrm{~mm}^{3}\right)$ with predominantly neutrophils, suggestive of infection. Blood culture was negative while urine culture revealed significant growth of Candida species indicative of urinary tract infection

Chest X-ray was suggestive of pneumonia. In conclusion, based on the above biochemical and 
microbiological findings, this patient had developed acute on chronic kidney failure secondary to severe dehydration due to HHS precipitated by pneumonia and urinary tract infection.

$\mathrm{HHS}$ is the most serious complication of diabetic decompensation, which is associated with high mortality. Glucose levels, serum osmolality, and blood $\mathrm{pH}$ and serum bicarbonate level with or without ketones confirmed the biochemical diagnosis of HHS. In addition, calculation of the effective osmolarity and corrected sodium and potassium values could help the clinician to guide the treatment and identify any precipitating illness. $\mathrm{HHS}$ is a preventable disease, so we advocate that early diagnosis and identification of patients at risk with consistent hyperglycaemic state monitoring may be necessary.

\section{References}

1. Schomer DL. Focal status epilepticus and epilepsia partialis continua in adults and children. Epilepsia 1993; 34: S29-36.

2. Maclsaac RJ, Lee LY, McNeil KJ, Tsalamandris C, Jerums G. Influence of age on the presentation and outcome of acidotic and hyperosmolar diabetic emergencies. Intern Med J 2002; 32: 379-85.

3. Nugent BW. Hyperosmolar hyperglycemic state. Emerg Med Clin North Am 2005; 23: 629-48.

4. Chiasson J, Aris-Jilwan N, Belanger R, et al. Diagnosis and treatment of diabetic ketoacidosis and the hyperglycemic hyperosmolar state. CMAJ 2003; 168: 859-66.

5. English P, Williams G. Hyperglycaemic crisis and lactic acidosis in diabetes mellitus. Postgrad Med 2004; 80: 253-61.

6. Kitabchi AE, Nyenwe EA. Hyperglycemic crises in diabetes mellitus: diabetic ketoacidosis and hyperglycemic hyperosmolar state. Endocrinol Metab Clin N Am 2006; 35: 725-51.

7. American Diabetes Association. Hyperglycemic crises in diabetes. Diabetes Care 2004; 27: S94-102.. 